\title{
RECURSOS HUMANOS PARA NOVOS CENÁRIOS
}

\author{
Angelo C. Pinto \\ Instituto de Química, Universidade Federal do Rio de Janeiro, CT, Bloco A, Cid. Univ. Ilha do Fundão, 21949-900 Rio de Janeiro - RJ, \\ Brasil \\ Cesar Zucco \\ Departamento de Química, Universidade Federal de Santa Catarina, CP 476, 88040-900 Florianópolis - SC, Brasil \\ Jailson B. de Andrade* \\ Instituto de Química, Universidade Federal da Bahia, 40170-290 Salvador - BA, Brasil \\ Paulo C. Vieira \\ Departamento de Química, Universidade Federal de São Carlos, CP 676, 13565-905 São Carlos-SP, Brasil
}

Recebido em 17/2/09; aceito em 17/3/09; publicado na web em 2/4/09

\begin{abstract}
HUMAN RESOURCES FOR NEW SCENARIOS. The Brazilian Chemical Society - SBQ has made substantial contributions to the formation of qualified human resources at all levels since its foundation in 1977. Several papers addressing this subject have been published in Quimica Nova by different authors over the last years. In this paper, we discuss the present need for "Curriculum Guidelines" for undergraduate education in Chemistry with actions to be taken in accord with the Principles of Green Chemistry and Sustainability.
\end{abstract}

Keywords: human resources; chemical education.

\section{INTRODUÇÃO}

Desde a sua criação, em 1977, a Sociedade Brasileira de Química (SBQ) tem se voltado para o avanço da Química e, em especial, dedicado sua atenção às pesquisas inovadoras e de desenvolvimento. ${ }^{1}$ A partir do início da década passada, a SBQ vem coordenando a discussão sobre a formação do Químico nos níveis de graduação e pós-graduação. Como consequência dessa nova vertente, diversos artigos foram gerados e publicados pela Química Nova, dentre os quais se destaca o documento Eixos Mobilizadores em Química ${ }^{2}$ em 2003 e, posteriormente, como seu desdobramento, um segundo documento, em 2004, A Formação do Químico, ${ }^{3}$ cuja meta era despertar e fomentar a discussão nas Instituições de Ensino Superior (IES), nas secretarias regionais da SBQ e na reunião específica desta Sociedade para a preparação e a consolidação de uma doutrina sobre o tema.

O incentivo à discussão sobre a formação de recursos humanos qualificados em todos os níveis fez acontecer, durante a 26a Reunião Anual da SBQ, ainda em 2003, o simpósio 4 "A Formação do Químico", quando diversos debatedores, incluindo representante da Indústria Química, discutiram a formação - real e desejada - dos profissionais da Química, graduação e pós-graduação, as repercussões dessa formação no ensino (médio e superior) e a inserção desses profissionais no setor industrial.

Em parceria com o Centro de Gestão e Estudos Estratégicos (CGEE), a SBQ promoveu, em outubro de 2004, o workshop "Química no Brasil: perspectivas e necessidades para a próxima década", ${ }_{5}^{5}$ visando analisar a atual configuração do processo de formação e de organização da pesquisa na área da Química e sua adequação às perspectivas e necessidades para as atividades econômicas e para o delineamento de políticas sociais no Brasil. Novamente, um dos itens foi a formação do Químico: desafios e necessidades, comprovando-se que a formação de pessoal é uma das preocupações da SBQ, sobretudo quando se trata da Química como componente de desenvolvimento socioeconômico do país. ${ }^{6}$

*e-mail: jailsong@ufba.br
Para melhor estruturar as ações voltadas para o ensino de Química, a SBQ criou, em 2005, o Fórum de Coordenadores de Cursos de Graduação em Química que, a exemplo do Fórum de Coordenadores de Programas de Pós-Graduação em Química (desde 1991), vem promovendo o encontro anual de coordenadores para discussão de temas de interesse desse nível de educação. Dessas discussões resultaram avaliações que apontaram a falta de qualidade que permeia o ensino superior brasileiro e, por extensão, o ensino da graduação em Química. ${ }^{7}$ Neste trabalho, serão discutidas as preocupações atuais com a formação de recursos humanos em Química, de forma interdisciplinar, prontos a enfrentar os desafios do novo século, notadamente com a sustentabilidade da vida.

\section{"QUÍMICA" - APARÊNCIA E CONVERGÊNCIA}

A produção industrial e a qualificação da força de trabalho são a base da riqueza de qualquer nação. E a Química é uma das principais áreas que, nas nações desenvolvidas e em desenvolvimento, tem participação importante nessa produção, seja para atender a um mercado interno, seja para exportação de produtos manufaturados.

Não obstante o reconhecimento de sua relevância na criação de riqueza, da abrangência de seu raio de ação e de sua interrelação com outras áreas do conhecimento, a Química é uma palavra aparentemente escondida. ${ }^{1,8}$ Pelo seu caráter central e invasivo, o conceito formal da Química, como disciplina, vem sendo ressignificado; seu conteúdo não mais é estudado isoladamente, mas como parte importante, subjacente e indispensável a outras matérias, temas ou disciplinas. $\mathrm{O}$ conhecimento, cada vez mais multifacetado, pressupõe um diálogo entre as várias áreas, ficando a Química, dada a sua natureza de processo fundamental, implícita aos conteúdos das demais matérias.

Esse entendimento está relacionado a dois relevantes fatos que devem ser considerados quando se pensa na formação de recursos humanos no século XXI: i) o desaparecimento, no final do século passado, das fronteiras disciplinares no âmbito das ciências naturais e o surgimento de domínios híbridos, mutáveis, convergentes e de elevada complexidade ${ }^{9}$ e ii) o reconhecimento, no início deste século, 
da convergência tecnológica que pretende a unificação da ciência e da tecnologia baseada na combinação da nanotecnologia, biotecnologia, tecnologia da informação e ciência cognitiva. ${ }^{10}$ Tanto a convergência científica quanto a tecnológica destacam que o principal foco é o tema em estudo e não a disciplina.

Nesta nova concepção, para enfrentar os desafios emergentes, torna-se necessária a união de ciência e educação, condição fundamental para a transformação radical da educação científica, do ensino fundamental à pós-graduação. A convergência de disciplinas científicas e de campos de pesquisa, historicamente separados, não poderá ocorrer sem a emergência de novos profissionais e cientistas que reconheçam quão multifacetados e profundos são os desafios científicos e tecnológicos e quão inteligente será o esforço necessário para integrá-los. ${ }^{1-3}$ Para isso, será necessária a construção de novos currículos, novas estruturas educacionais e novos caminhos que busquem a coerência intelectual. Os princípios da Química Verde, a sustentabilidade e a atuação responsável deverão ser transversais aos novos currículos e às novas estruturas.

A Química Verde deve deixar de ser apenas um conceito, para ser uma atitude responsável, em que a atividade química não agrida o meio ambiente, eliminando-se ou minimizando-se, ao máximo, a produção de rejeitos e de solventes agressivos ao ambiente. Para tanto, precisamos "inocular" nos estudantes e profissionais o "comportamento verde".

Nesse novo cenário, a inovação emerge como o principal combustível para a longevidade das corporações, reforçando os desafios anteriormente apontados e destacando os fatores críticos para seu sucesso quais sejam: i) pessoal (que define o ambiente inovativo); ii) processos (que requerem boas práticas e padronização); e iii) parcerias (que proveem o conhecimento, entendimento e habilidades, em tempo real, para a rápida inovação).

Os termos invenção e inovação são termos-chave na era industrial moderna e, ao mesmo tempo, inerentes à própria natureza da Química. Inventar e inovar são, pois, dois verbos que devem ser incorporados à cultura dos cursos técnicos e superiores de Química.

Modificar a visão disciplinar convencional na formação científica e profissional, e nas atividades de ciência, tecnologia e inovação envolve uma reformulação conceitual e institucional, pois a configuração departamental atual reflete a divisão disciplinar. ${ }^{1}$ Logo, é preciso avançar para um sistema acadêmico com foco além dos Departamentos, que inclua "Estruturas de Excelência", do tipo Institutos, Núcleos, Centros, onde o ambiente multi e interdisciplinar predomine. ${ }^{4,11}$ Nesses, o estudante deverá ter formação sólida e abrangente que lhe permita ultrapassar a fronteira das disciplinas e subáreas envolvidas e que o habilite a atuar de forma interdisciplinar. No novo ambiente, haverá estímulo ao desenvolvimento de projetos de graduação, iniciação científica e de pós-graduação, sob a supervisão de mais de um professor orientador, permitindo que o estudante vivencie um ambiente profissional no qual a atuação em equipes interdisciplinares e o trabalho em redes sejam cada vez mais estimulados e exigidos.

\section{INTERDISCIPLINARIDADE E SUSTENTABILIDADE}

Os principais desafios do século XXI incluem majoritariamente a Química, mas não são reconhecidos pela sociedade como problemas químicos! Energia, Água, Alimentos e Ambiente estão interrelacionados, requerem abordagem interdisciplinar e são a base da sustentabilidade da humanidade e do planeta. $\mathrm{O}$ crescimento atual da demanda energética é significativo e não poderá ser suprido apenas pelas atuais fontes, em especial os combustíveis fósseis (óleo, carvão e gás natural) que representam mais de $75 \%$ da matriz energética mundial. A queima de petróleo, carvão e gás natural tem contribuído fortemente para o crescimento das concentrações de dióxido de carbono na atmosfera, com reflexos danosos no clima global do planeta. Assim, muitos dos problemas ambientais dependem diretamente da forma como a energia é produzida e/ou usada. Atualmente, estima-se que 1,3 bilhão de pessoas vivam em locais em que a qualidade do ar é inadequada.

Nos próximos 50 anos, as necessidades de demanda de energia atingirão cerca de 30 a $60 \mathrm{TW}$, e a sustentabilidade ambiental requer que as fontes sejam limpas e de baixo custo. No cenário energético atual, um novo conceito emergiu: a "segurança energética", que significa muito mais do que proteger refinarias e oleodutos contra ataques terroristas. Segurança energética pode ser compreendida como a capacidade de manter a máquina global funcionando, isto é, produzindo combustíveis e eletricidade suficientes, a preços acessíveis, para que todos os países possam, pelo menos, manter sua economia operando e o seu povo alimentado. No caso das economias emergentes, como Brasil, Índia e China, a demanda de energia está aumentando tão rapidamente que pode dobrar até 2020, o que coloca a questão energética e ambiental como uma questão global. Nesse contexto, um dos principais desafios é produzir, estocar e transportar combustíveis derivados de biomassa (e.g. etanol e biodiesel), hidrogênio e metanol, de forma sustentável, bem como captar, estocar e transportar energia solar.

Diretamente associadas à questão energética e ambiental estão a produção de alimentos, a segurança alimentar e o acesso à água em quantidade e qualidade para consumo humano e animal. Existem locais sem acesso à água, e estima-se que um bilhão de pessoas não têm acesso à água com qualidade adequada para o consumo. $\mathrm{O}$ trinômio água-alimentos-energia precisa ser abordado de forma sustentável, pois, por exemplo, a produção de $1 \mathrm{~kg}$ de soja, base seca, consome cerca de 600 a $1.000 \mathrm{~kg}$ de água!

Nesse sentido, a interdisciplinaridade e a sustentabilidade devem estar presentes durante todo o processo de formação do Químico, pois delas depende a criação do "comportamento verde". A formação do Químico precisa ser feita num ambiente que explicite os caminhos da sustentabilidade, com destaque à produção de energia, de alimentos, de tecnologias de purificação e minimização do uso da água e, acima de tudo, da preservação do ambiente e do bem-estar da humanidade. ${ }^{12}$ Essencialmente, o ensino de Química precisa ser feito de forma a destacar o papel dos conceitos em outras disciplinas, em especial nas ciências da vida. A interação com a biologia, por exemplo, já está presente na pós-graduação e na pesquisa, enquanto, infelizmente, está totalmente ausente no ensino de graduação.

\section{A FORMAÇÃO DO PROFESSOR DE QUÍMICA}

Nesse novo cenário, a formação do professor de Química deverá ter atenção especial, pois necessitará de, pelo menos duas vertentes: i) a formação em Cursos de Licenciatura convencionais que o estimule também a atuar em faculdades e universidades, como possibilidade ampla de realizar estudos de pós-graduação em todos os níveis; ii) a formação emergencial de professores de Química para os níveis médio e fundamental. Esta deverá, inovativamente, prever um sistema sequencial de formação que permita ao licenciando atuar como professor a partir do segundo ano, no mínimo, com atividades de gestão escolar distribuídas ao longo do curso, permitindo que, ao completar a licenciatura, este possa receber uma especialização nos moldes do "Master in Business Administration, MBA".

É amplamente conhecida a necessidade do país de garantir que o ensino de Ciências (Biologia, Física, Matemática e Química) no ensino médio seja realizado por profissionais qualificados. Entretanto, o déficit de professores graduados nessas áreas é significativamente grande. Dados disponíveis no INEP $^{13}$ mostram que dos 62 mil 
docentes em exercício na Educação Básica, responsáveis pela disciplina Química, apenas cerca de 8 mil têm Licenciatura específica em Química, e que cerca de 75\% dos licenciados em Química não atuam no magistério na educação básica. Por outro lado, a maioria dos professores graduados que atuam no ensino médio não o são em Biologia, Física, Matemática e Química e carecem de atualização na sua formação profissional que resulte em melhoria de conteúdos, didática e visão integrada da ciência.

Um novo modelo de curso, Licenciatura Especial em Química, alternativo e complementar às licenciaturas convencionais, deve buscar viabilizar além da qualificação profissional dos docentes, o papel "multiplicador" desses professores, dotando-os de competências para desenvolver novas metodologias de ensino, programar workshops e Feiras de Ciências, gerenciar políticas de educação científica e de avaliação. Deve contribuir também para a ampliação das atividades experimentais nos respectivos cursos que resulte na formação de jovens com conhecimento consolidado em ciências, buscando despertar vocações futuras. Espera-se, ainda, que os professores oriundos do novo curso sejam multiplicadores entre seus pares, ministrando cursos de atualização, aperfeiçoamento e especialização, que resulte na valorização do professor do Ensino Médio.

Na elaboração do currículo, deve-se evitar a pulverização dos conteúdos num exagerado número de disciplinas, que segmentam o conhecimento, deixando de ressaltar o essencial. Além disso, a compartimentalização leva à repetição desnecessária de conteúdos. Mais do que o domínio cognitivo do conteúdo de Ciências, o novo currículo deve contemplar atividades que estabeleçam correlações entre áreas conexas (Biologia, Física, Matemática e Química), ampliando o caráter interdisciplinar. A composição curricular poderia ser elaborada de tal forma que permitisse ao egresso uma licenciatura (Major) em Química e outra (Minor) em Biologia, Física ou Matemática.

Assim, o currículo deve buscar a integração entre os conteúdos básicos e os conteúdos profissionais essenciais e promover, também, por meio de seus planos de ensino, condições reais e quantitativamente significativas de integração de atividades e experiências práticas em laboratórios e estágios. Nesse sentido, é sugerida a seguinte composição para o quadro ${ }^{14}$ curricular:

i) conteúdos básicos essenciais para a formação comum e interdisciplinar; envolvendo teoria e laboratório e dos quais deverão fazer parte: Biologia, Matemática, Física e Química;

ii) conteúdos profissionais essenciais para o desenvolvimento de competências e habilidades; envolvendo aprofundamento em subáreas específicas de Química, e da disciplina escolhida para a obtenção do Minor, formação didático-pedagógica, administração, história, ciência do ambiente e uso de novas tecnologias;

iii) conteúdos complementares essenciais para a formação humanística, interdisciplinar, gerencial; envolvendo o estudo da evolução da ciência, ética, iniciação científica, conciliência e elaboração de artigos e monografias e leitura de textos selecionados relacionados com ciências;

iv) atividades extra-classe essenciais para estimular o professor a buscar atividades acadêmicas e de prática profissional alternativas, como a participação e a apresentação de trabalhos e/ou resumos em seminários, conferências, semanas de estudos e similares, a publicação de artigos em revistas ou outros meios bibliográficos e/ou eletrônicos especializados, a organização de workshops, boletins, feiras de ciências e experimentos para mostra em museus.

Com relação às habilidades a serem desenvolvidas durante o curso, este pode ser estruturado de forma a possibilitar a formação abrangente e interdisciplinar requerida do educador. Para tanto, o licenciando deverá ter a oportunidade de vivenciar experiências de ensino-aprendizagem, por meio do contato com docentes, palestrantes e literatura. Deverá, igualmente, participar de atividades de planejamento de ensino com formulação de problemas e busca de soluções, e avaliação de situações de ensino-aprendizagem.

As experiências de aprendizagem desenvolvidas no curso precisam ultrapassar as tradicionais técnicas usadas em sala de aula ou em laboratórios de demonstração e prever o melhor aproveitamento possível das horas-atividade programadas. Isso inclui criar condições e incentivo para que os estudantes tenham atualização em informática - necessária para o acompanhamento tecnológico da informática educacional e instrucional e para o desenvolvimento de habilidade no uso do acervo existente em bibliotecas, inclusive nas modalidades eletrônica e remota, o que lhes permitirá contínua atualização técnica e científica.

O curso de Licenciatura Especial em Química será planejado para ser concluído em oito semestres, sequencialmente, e todos os estudantes deverão ser bolsistas de "iniciação à docência", durante todo o curso, desde que tenham bom aproveitamento. A partir do terceiro semestre, os estudantes terão carga horária em Colégios Públicos da respectiva região. A combinação do curso com atividade profissional é especialmente relevante na formação do professor.

Após a conclusão da licenciatura, os agora docentes poderão desenvolver, paralelamente às atividades didáticas, um trabalho de dissertação, envolvendo, necessariamente, temas relacionados com suas atividades didáticas ou de extensão escolar para o ensino médio. Aos que tiverem o trabalho de dissertação aprovado em programa de pós-graduação, credenciado pela CAPES, será concedido o título de "mestre em docência". Este modelo de licenciatura poderá ser utilizado nas varias áreas do conhecimento.

A discussão sobre como recuperar e fortalecer a identidade da Química, como uma das formas de fortalecê-la, num cenário de mudanças onde as fronteiras disciplinares se tornam cada vez mais invisíveis, deve ser travada nos Colegiados dos Cursos de Química, sem que se perca de vista que o fortalecimento desses Cursos passa, antes de tudo, pela atração de estudantes motivados e bem preparados.

Um bom exemplo para fomentar esta discussão é o artigo recém-publicado no jornal Washington Post pelo Presidente dos EUA, Barack Obama, em que, mais uma vez, foi enfatizada a importância do estudo de Ciências e de Matemática para a manutenção da supremacia econômica americana. Nesse mesmo documento foi traçada uma meta de dobrar, em três anos, a capacidade na geração de fontes alternativas de energia, para tirar os EUA da dependência energética do petróleo.

\section{O SETOR INDUSTRIAL QUÍMICO}

Em 2007, o faturamento líquido da indústria química brasileira, considerando todos os segmentos que a compõem, alcançou 201,6 bilhões de reais, $12,2 \%$ acima do de $2006 .{ }^{15} \mathrm{O}$ Brasil tem a segunda indústria química do continente americano, atrás apenas dos Estados Unidos da América, e está entre os dez mais importantes no ranking mundial. O setor industrial químico enfrenta, neste século, o grande desafio da sustentabilidade: que é um caminhar que permite à humanidade, no presente, encontrar o bem-estar humano e ambiental e satisfazer suas necessidades econômicas e sociais, sem comprometer o progresso e o sucesso das futuras gerações. ${ }^{16}$ A sustentabilidade envolve produtos, processos, energia, competitividade econômica e, especialmente, não agredir o ambiente e a vida.

Neste século, o grande consumo de matéria-prima deve ser substituído, em vários setores, pela reciclagem. O Brasil já é um exemplo na produção de alumínio. A energia economizada com a reciclagem de latas de refrigerante e cerveja em relação à produção industrial é suficiente para manter uma cidade do porte de Campinas, SP, “acesa"! Este princípio precisa ser adotado por outros segmentos 
industriais. Outras duas mudanças significativas são a migração do uso intensivo de combustíveis fósseis para o uso de energia renovável e a transição do controle de efluentes para a economia de átomos. Essas transições representarão, pelo menos, economia de recursos e proteção ao ambiente e à vida (Figura 1).

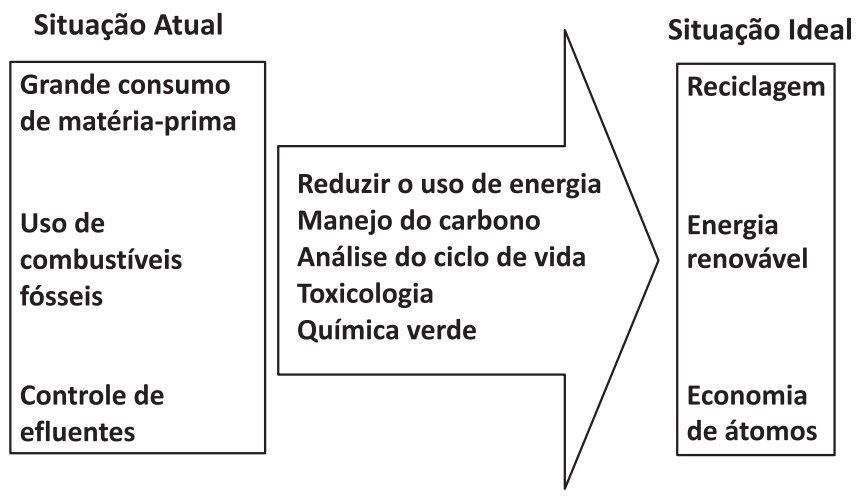

Figura 1. Grandes desafios da sustentabilidade do Setor Industrial Químico. Adaptada da ref. 16

Para atingir uma situação próxima à ideal, é de vital importância incluir nos cursos de formação de Químicos, com destaque, o enfoque na redução do uso de energia nos processos químicos, manejo de carbono, análise do ciclo de vida e da toxicologia e utilizar os princípios da Química Verde, de forma transversal, durante todo o período de formação.

A articulação dos cursos de Química com o setor industrial é de extrema relevância. O que se observa atualmente é que os cursos de pós-graduação em Química são mais articulados com o setor industrial do que os de graduação. Novamente, graduação e pós-graduação em Química andam em mãos opostas.

\section{CONCLUSÕES}

Para enfrentar os desafios dos tempos atuais, em que os mercados de trabalho são cada vez menos previsíveis e se alteram em curto espaço de tempo, é necessário mudar a estrutura dos cursos de graduação e a forma de ensinar. Ciência, técnica e tecnologia correspondem a um trinômio indissociável, e a educação é um processo permanente. Hoje, aprende-se ao longo de toda a vida, cujo aumento de expectativa nos últimos 40 anos, ocorreu, graças, em parte, ao avanço da Química. Viver mais e melhor depende, principalmente, do progresso da ciência e do domínio de novas tecnologias. Isto requer mudança de atitudes e da forma de ensinar, e da reorganização dos cursos. Nos cursos de Química, os currículos deverão incluir Programas Temáticos que integrem ciência e educação, e a avalanche de disciplinas teóricas que soterra os estudantes, cujos conteúdos, muitas vezes, se repetem ao longo do curso, deve ser substituída por um elenco de problemas para os quais os estudantes, individualmente ou em gru- po, procurem encontrar soluções. Os estudantes de Química devem aprender desde o início do curso a importância que a propriedade intelectual representa para a riqueza nacional. Invenções, sejam elas incrementais ou radicais, só se transformam em riqueza se forem protegidas por patentes. ${ }^{17}$

As Licenciaturas em Química deverão também formar professores para o Ensino Médio que, além do domínio de conteúdos, sejam conscientes da missão de formar cidadãos que reconheçam a importância da ciência para o bem-estar da humanidade.

\section{AGRADECIMENTOS}

À Sociedade Brasileira de Química e ao Prof. F. Galembeck pelo convite para contribuir com este Número Especial de Química Nova.

\section{REFERÊNCIAS}

1. de Andrade, J. B.; Pinto, A. C.; Cadore, S.; Vieira, P. C.; Zucco, C.; Pardini, V. L.; Curi, L. R. L.; Quim. Nova 2005, 28 Suplemento, S7.

2. de Andrade, J. B.; Cadore, S.; Vieira, P. C.; Zucco, C.; Pinto, A. C., Quim. Nova 2003, 26, 445.

3. de Andrade, J. B.; Cadore, S.; Vieira, P. C.; Zucco, C.; Pinto, A. C.; Quim. Nova 2004, 27, 358.

4. de Andrade, J. B.; Galembeck, F.; Gandur, M. C.; Livro de Resumos da 26a Reunião Anual da SBQ, Poços de Caldas, Brasil, 2003.

5. Workshop Química no Brasil: perspectivas e necessidades para a próxima década. Promoção do Centro de Gestão e Estudos Estratégicos, CGEE, e da Sociedade Brasileira de Química, SBQ, ocorrida na Sede do Conselho Regional de Química de São Paulo, Rua Oscar Freire, 2039 - Pinheiros - São Paulo, em 27 e 28 de outubro de 2004.

6. Zucco, C.; Quim. Nova 2005, 28 Suplemento, S11.

7. Zucco, C.; Quim. Nova 2007, 30, 1429.

8. http://www.iupac2009.org, acessada em Fevereiro 2009.

9. Wilson, E.; Consiliência, Editora Campus, 1998.

10. Converging Technologies for Improving Human Performance; Roco, C.; Brainbridge, M. C.; Bainbridge, W. S.; NSF/DOC-sponsored report, June 2002.

11. Rebouças, M. V.; de Andrade, J. B.; Pinto, A. C.; Quim. Nova 2005, Suplemento, S14.

12. Silva, L. S.; de Andrade, J. B.; Química Nova na Escola 2003, n. 5, 3.

13. www.inep.gov.br, acessada em Fevereiro 2009.

14. Zucco, C.; Pessine, F. B. T.; de Andrade, J. B.; Quim. Nova 1999, 22, 454.

15. http://www.abiquim.org.br/conteudo.asp?princ=ain\&pag=estat, acessada em Fevereiro de 2009.

16. Sustainability in the Chemical Industry: Grand Challenges and Research Needs - A Workshop Report, http://www.nap.edu/catalog/11437.html, acessada em Fevereiro 2009.

17. de Oliveira, L. G.; Suster, R.; Pinto, A. C.; Ribeiro, N. M.; da Silva, R. B.; Quim. Nova 2005, 28 Suplemento, S36. 